\title{
PENGARUH BUDAYA ORGANISASI TERHADAP ORGANIZATIONAL CITIZENSHIP BEHAVIOR DENGAN PEMEDIASI KOMITMEN AFEKTIF DI SEKRETARIAT KABUPATEN BADUNG
}

\author{
Ayu Putu Ariani ${ }^{1}$ \\ Desak Ketut Sintaasih ${ }^{2}$ \\ Made Surya Putra ${ }^{3}$ \\ ${ }^{1,2,3}$ Fakultas Ekonomi dan Bisnis Universitas Udayana (Unud), Bali, Indonesia \\ e-mail: toearik@yahoo.com
}

\begin{abstract}
ABSTRAK
Tujuan penelitian ini adalah untuk menguji signifikansi pengaruh budaya organisasi terhadap komitmen afektif, pengaruh komitmen afektif terhadap OCB, pengaruh budaya organisasi terhadap OCB dan efek mediasi komitmen afektif pada pengaruh budaya organisasi terhadap OCB. Sampel penelitian berjumlah 83 pegawai yang ditentukan dengan menggunakan metode proportionate random sampling. Data penelitian diperoleh dari penyebaran kuesioner dan wawancara. Alat analisis yang digunakan dalam penelitian ini menggunakan Partial Least Square (PLS). Hasil penelitian menunjukkan bahwa budaya organisasi berpengaruh positif terhadap komitmen afektif, semakin baik budaya organisasi maka komitmen afektif juga semakin kuat. Komitmen afektif berpengaruh positif terhadap OCB, semakin kuat komitmen afektif yang dianut maka perilaku OCB juga semakin tinggi. Budaya organisasi berpengaruh positif terhadap OCB, semaik baik budaya organisasi yang diterapkan maka OCB juga semakin tinggi. Hasil pengujian hipotesis selanjutnya dihasilkan bahwa komitmen afektif memediasi secara parsial pada pengaruh budaya organisasi terhadap OCB..
\end{abstract}

Kata Kunci: Budaya organisasi, komitmen afektif dan $O C B$

\begin{abstract}
The purpose of this study was to determine the significance of the influence of organizational culture on affective commitment, the influence of affective commitment on $O C B$, the influence of organizational culture on $O C B$ and the mediating effect of affective commitment on the influence of organizational culture on $O C B$. These samples included 83 employees are determined using proportionate random sampling method. Data were obtained from questionnaires and interviews. The analytical tool used in this study using Partial Least Square (PLS). The results showed that organizational culture positive effect on affective commitment, the better the culture of the organization, affective commitment is also getting stronger. Affective commitment positively affects the $O C B$, the stronger the affective commitment has embraced the OCB behaviors also higher. Organizational culture positive influence on $O C B$, semaik both an organizational culture that is applied then OCB also higher. Results of testing the hypothesis is further produced that affective commitment partially mediates the influence of organizational culture on $O C B$
\end{abstract}

Keywords: organizational culture, affective commitment and OCB 


\section{PENDAHULUAN}

Kinerja pelayanan publik merupakan hal penting yang menjadi perhatian dari semua pihak karena berkaitan dengan pertanggungjawaban pemerintah terhadap amanah rakyat. Reformasi sektor publik yang terjadi di berbagai tempat adalah upaya untuk meningkatkan kinerja pelayanan publik sehingga tercapai suatu kondisi pemerintahan yang efisien, efektif, responsif dan akuntabel (Nawangsari, 2014). Peningkatan kinerja pelayanan publik dapat dicapai dengan berupaya mengoperasikan seluruh sumber daya yang dimiliki baik, sumber daya finansial, fisik, sumber daya manusia (SDM), organisasi, kemampuan teknologis, dan sistem (Hasibuan, 2007).

Eksistensi Undang-undang Pelayanan Publik yang telah berjalan sejak tahun 2009 merupakan hal yang telah dilaksanakan oleh setiap daerah untuk dapat memberikan pelayanan publik yang lebih baik kepada masyarakat. Diberlakukannya Undang-undang No. 25 Tahun 2009 Tentang Pelayanan Publik, memberikan lebih banyak kewenangan kepada daerah dalam menjalankan fungsi umum pemerintah, yaitu pelayanan publik. Undang-undang tersebut merupakan landasan yuridis bagi pengembangan pelayanan publik di Indonesia.

Pemerintah Indonesia telah melakukan beberapa perubahan mendasar guna meningkatkan kinerja layanan publik, seperti diberlakukannya otonomi daerah dan adanya perundang-undangan yang berkaitan dengan perbaikan manajemen pemerintah yaitu dengan diundangkannya Otonomi Daerah melalui Undang Undang No.22 Tahun 1999 (direvisi dengan Undang - undang No. 32 Tahun 2004). 
Peraturan Daerah Kabupaten Badung Nomor 7 Tahun 2008 tentang Pembentukan, Organisasi dan Tata Kerja Perangkat Daerah Kabupaten Badung menyebutkan bahwa Sekretariat Daerah memiliki fungsi dan kewajiban untuk membantu Bupati dalam menyusun kebijakan dan mengkoordinasikan Dinas Daerah dan Lembaga Teknis Daerah. Pemantauan dan evaluasi pelaksanaan kebijakan Pemerintahan Daerah, pembinaan administrasi dan aparatur Pemerintahan Daerah. Sekretariat Daerah dengan segala fungsi dan kewajiban yang dimiliki maka diharapkan para pegawainya memiliki prinsip-prinsip dan nilai-nilai budaya organisasi dan komitmen yang tinggi terhadap organisasi dalam rangka meningkatkan kualitas dan produktivitas sesuai dengan tugas pokok dan fungsinya.

Budaya organisasi yang terdapat pada Sekretariat Daerah Kabupaten Badung tidak terlepas dari prinsip-prinsip Good Corporate Governance (GCG) yaitu transparansi, kemandirian, akuntabilitas, pertanggungjawaban dan kewajaran. Transparansi berkaitan dengan keterbukaan dalam melaksanakan proses pengambilan keputusan dan relevan dalam menyampaikan informasi keuangan dan non keuangan bagi pihak yang berkepentingan. Kemandirian berkaitan dengan pengelolaan organisasi secara professional tanpa benturan kepentingan, pengaruh dan tekanan dari pihak manapun yang tidak sesuai dengan peraturan perundang-undangan yang berlaku dan prinsip-prinsip organisasi. Akuntabilitas berkaitan dengan kejelasan fungsi, pelaksanaan dan pertanggung jawaban masing-masing bidang dan sub bidang sehingga pengelolaan berjalan secara efektif. Pertanggungjawaban berkaitan dengan kesesuaian di dalam 
melaporkan pelaksanaan kewajiban secara tepat waktu berdasarkan anggaran yang telah disetujui. Kewajaran berkaitan dengan keadilan dan kesetaraan di dalam memenuhi hak-hak stakeholder sesuai dengan peraturan perundang-undangan yang berlaku. Hal tersebut semakin dipertajam pelaksanaannya pada masing masing instansi dengan telah dilaksanakannya pemeriksaan berkala oleh Badan Pemeriksa keuangan tentang kinerja keuangan dan capaian target realisasi Anggaran Pendapatan dan Belanja Daerah Kabupaten Badung setiap tahunnya. Serta untuk mengevaluasi sejauhmana keberhasilan kegiatan yang diprioritaskan kepada masyarakat telah menyentuh kepada kepentingan masyarakat Kabupaten Badung.

Fenomena yang terjadi pada Sekretariat Daerah Kabupaten Badung adalah tidak semua pegawai yang memiliki kemampuan kerja tinggi mau membantu rekan kerja atau atasannya dalam menyelesaikan masalah pekerjaan yang tidak ada hubungan dengan tugas dan bidangnya, Seperti kenyataan yang terjadi apabila ada salah satu meja yang fungsinya melayani proses pensertifikatan tanah aset pemerintah, pada saat yang bersangkutan berhalangan hadir dan ada yang membutuhkan informasi tentang hal tersebut, tidak dengan serta merta rekan yang lain yang berada dalam satu ruangan dapat memberikan informasi tentang hal yang dibutuhkan. Penyebabnya adalah keterbatasan kemampuan dan pengetahuan yang dimiliki oleh beberapa pegawai terhadap hal tersebut sehingga merasa takut untuk memberikan informasi.

Proses pengembangan kemampuan pegawai yang dilaksanakan oleh Pemerintah Kabupaten Badung adalah dengan melakukan beberapa pendidikan 
dan pelatihan tentang program-program baru yang akan diterapkan oleh Pemerintah Kabupaten Badung. Kenyataan yang terjadi, dari sejumlah pegawai yang ditugaskan untuk mengikuti diklat tersebut, tidak seluruhnya dapat menyerap materi yang telah diberikan dan mampu mengaplikasikan dalam kegiatan di masing masing bagiannya. Beberapa pegawai memilih menghindar untuk ditugaskan mengaplikasikan program baru tersebut dengan berdalih kurang paham terhadap teknologi. Jelas terlihat bahwa beberapa pegawai memiliki keengganan untuk terlibat dalam program organisasi dan mengadopsi misi organisasi. Kerjasama tim belum dirasakan sebagai suatu hal yang penting oleh beberapa pegawai, karena ada kecenderungan beberapa pegawai acuh terhadap tugas yang dibebankan pada organisasinya. Secara tidak langsung hal tersebut berpengaruh terhadap kualitas layanan yang diberikan masing masing bagian baik itu terhadap instansi lain maupun terhadap masyarakat.

Podsakoff et al. (2000), menyatakan bahwa organizational citizenship behavior merupakan sebuah istilah yang pertama kali diperkenalkan oleh Dennis W.Organ pada tahun 1988. Menurut Organ (1988), organizational citizenship behavior merupakan perilaku-perilaku individu yang bersifat opsional (discretionary), yang secara tidak langsung ataupun secara eksplisit diperhitungkan dalam sistem-sistem penghargaan formal dan secara agregatif mempromosikan fungsi-fungsi dari organisasi menjadi lebih efektif.

Menurut Khan dan Rashid (2012), komitmen organisasi merupakan variabel yang paling berpengaruh dalam menjelaskan peranan organizational citizenship behavior pada karyawan. Ketika nilai-nilai yang dimiliki oleh perusahaan 
memiliki "service value" maka organizational citizenship behavior akan muncul pada karyawan (Ahmadi, 2010). Penelitian Sabri et al (2011) terhadap para tenaga pengajar di berbagai institusi pendidikan tinggi dan universitas yang ada di Pakistan menyatakan bahwa budaya organisasi memiliki hubungan yang positif dan signifikan terhadap komitmen organisasional.

Budaya organisasi yang terdiri dari dua dimensi yaitu faktor perilaku dan faktor struktural, dimana kedua dimensi ini memiliki hubungan yang signifikan terhadap organizational citizenship behavior (Ebrahimpour et al. 2011). Kim (2014), dalam penelitiannya menyebutkan bahwa komitmen afektif terhadap Organizational Citizenship Behavior memiliki hubungan yang signifikan sejalan dengan budaya organisasi memiliki hubungan yang signifikan dengan komitmen afektif, sedangkan tidak terdapat hubungan yang signifikan antara budaya organisasi terhadap Organizational Citizenship Behavior, dan komitmen afektif secara penuh memediasi antara budaya organisasi dengan Organizational Citizenship Behavior. Oemar (2013) menyatakan bahwa budaya organisasi berpengaruh positif dan signifikan secara parsial terhadap organizational citizenship behavior (OCB) pegawai pada Bappeda Kota Pekanbaru. Kurniawan (2015) menyatakan bahwa tidak terdapat hubungan yang signifikan antara komitmen organisasional afektif dengan OCB.

Budaya organisasi memiliki peran vital dalam organisasi karena merupakan kebiasan-kebiasaan yang terjadi dalam hirarki organisasi yang mewakili norma-norma perilaku yang diikuti oleh para anggota organisasi, budaya organisasi yang kuat mengindikasikan tingginya loyalitas dan komitmen pegawai 
terhadap organisasi, sehingga dapat mengarahkan organizational citizenship behavior dari pegawai (Robbins, 2006). Organizational citizenship behavior yang dimiliki oleh pegawai berkembang seiring dengan proses sosialisasi dan nilai-nilai yang ada pada organisasi, ketika nilai-nilai itu memiliki makna yang kuat maka organizational citizenship behavior akan muncul dalam perilaku pegawai, hal ini secara tidak langsung berpengaruh kepada kualitas pelayanan yang diberikan oleh pegawai (Ahmadi,2010).

Apabila budaya organisasi yang tercipta di organisasi sudah baik dan nyaman serta pemahaman yang dimiliki oleh anggota organisasi terhadap budaya organisasi sudah tinggi maka kecenderungan untuk anggota organisasi memiliki komitmen terhadap organisasi juga akan tinggi. Dengan tingginya komitmen yang dimiliki oleh anggota organisasi maka akan muncul perasaan bangga terhadap organisasi dan perasaan bahwa organisasi tersebut memiliki arti yang begitu besar terhadap dirinya. Apabila budaya organisasi yang tercipta sudah baik dan pemahaman budaya organisasi karyawan juga tinggi maka perilaku OCB akan tercipta dengan baik dengan dimediasi oleh komitmen organisasi yang tinggi dari karyawan akan mendukung terciptanya perilaku OCB dari karyawan. Demikian pula sejalan dengan komitmen organisasi karyawan yang tinggi maka perilaku OCB akan terbentuk dengan baik.

Budaya organisasi yang diterapkan pada Sekretariat Daerah Kabupaten Badung seperti kemampuan organisasi untuk beradaptasi dengan lingkungan masyarakat yang dilahirkan melalui program dan kegiatan yang mengutamakan kepentingan masyarakat serta adanya arah serta tujuan organisasi yang jelas yang 
diturunkan menjadi rencana strategis Kabupaten Badung yang tersusun dari visi dan misi Kabupaten Badung. Hal ini akan memunculkan rasa bangga dari pegawai akan organisasinya, sehingga meningkatkan komitmen afektif yang dimiliki oleh pegawai. Perasaan bangga terhadap organisasi ini akan meningkatkan kecintaan terhadap instansinya sehingga mampu memunculkan perilaku peran ekstra diluar tugas dan fungsinya dalam instansi.

Berdasarkan latar belakang tersebut di atas, penelitian ini menguji dan menganalisis pengaruh budaya organisasi terhadap organizational citizenship behavior yang dimediasi oleh komitmen afektif dalam konteks organisasi publik. Subyek penelitian adalah pegawai (PNS) di Sekretariat Daerah Kabupaten Badung.

Kim (2014) menyatakan bahwa budaya organisasi berpengaruh signifikan terhadap komitmen afektif. Studi Momeni et al. (2012) mengenai pengaruh budaya organisasi terhadap komitmen organisasi, dengan menggunakan model dimensi budaya organisasi dari Denison (1990), diperoleh kesimpulan bahwa terdapat hubungan yang signifikan antara semua komponen budaya organisasi yang meliputi adaptability, involvement, adjustment, mission dan komitmen organisasi. Nongo dan Ikyanyon (2012) dalam studinya pada karyawan usaha kecil dan menengah di Makurdi, menyatakan bahwa involvement dan adaptability berhubungan signifikan dengan komitmen organisasi, sedangkan consistency dan mission tidak berhubungan dengan komitmen organisasi. Rini, dkk (2013) menyatakan bahwa budaya organisasi berpengaruh positif terhadap komitmen 
organisasi, semakin baik budaya organisasi yang tercipta maka komitmen organisasi karyawan akan semakin tinggi.

Berdasarkan uraian hasil penelitian di atas, maka dapat dihipotesiskan :

$\mathbf{H}_{\mathbf{1}}$ :Budaya Organisasi berpengaruh positif terhadap komitmen afektif.

Srimulyani (2009) yang menyatakan bahwa karyawan yang memiliki komitmen afektif yang tinggi akan memiliki kedekatan emosional yang erat dengan organisasinya sehingga karyawan akan memiliki motivasi dan kontribusi yang besar bagi organisasi. Oemar (2013) menyebutkan komitmen organisasi berpengaruh positif dan signifikan secara parsial terhadap organizational citizenship behavior (OCB) pegawai pada Bappeda Kota Pekanbaru. Kondisi ini menunjukkan jika komitmen organisasi meningkat maka Organizational Citizenship Behavior (OCB) pegawai pada Bappeda Kota Pekanbaru juga mengalami peningkatan, demikian pula sebaliknya. Salehi dan Gholtash (2011) yang melakukan studi pada bidang akademis, diperoleh hasil bahwa komitmen organisasi berpengaruh positif terhadap Organizational Citizenship Behavior (OCB), semakin besar komitmen anggota fakultas terhadap akademisinya, makin besar OCB anggota yang diharapkan.

Kim (2012) ; Lavelle et al.(2009) ;MacKenzie et al. (2001);Wagner and Rush (2000) mengemukakan bahwa banyak riset yang telah dilakukan di Amerika Utara yang meneliti tentang hubungan antara Affective Commitment dan Organizational Citizenhip Behavior dan ditemukan bahwa ada hubungan yang signifikan antara Affective Commitment dengan Organizational Citizenhip Behavior. Kim (2014) mengemukakan bahwa ada hubungan yang signifikan 
antara Affective Commitment dan Organizational Citizenhip Behavior pada organisasi sektor publik di Korea Selatan. Khaola et al.(2015) menyebutkan bahwa ada pengaruh yang signifikan antara komitmen organisasi dan Organizational Citizenship Behavior (OCB). Rini,dkk (2013) menyatakan bahwa terdapat hubungan yang signifikan antara budaya organisasi dengan Organizational Citizenship Behavior (OCB), semakin tinggi komitmen anggota organisasi maka akan terbentuk perilaku Organizational Citizenship Behavior (OCB).

Berdasarkan uraian hasil penelitian di atas, maka dapat dihipotesiskan :

$\mathbf{H}_{2}$ : Komitmen afektif berpengaruh positif terhadap Organizational Citizenhip Behavior.

Oemar (2014) menyatakan Budaya organisasi berpengaruh positif dan signifikan secara parsial terhadap organizational citizenship behavior (OCB) pegawai pada Bappeda Kota Pekanbaru, kondisi ini menunjukkan jika budaya organisasi semakin kuat maka Organizational Citizenship Behavior (OCB) pegawai pada Bappeda Kota Pekanbaru juga mengalami peningkatan demikian pula sebaliknya. Erkutlu (2011) menyatakan bahwa budaya organisasi mampu menjelaskan dan memberikan peranan yang penting dalam hubungan antara keadilan organisasi dan Organizational Citizenship Behavior (OCB) dalam suatu organisasi. Rini dkk (2013) menyebutkan bahwa terdapat hubungan yang signifikan antara budaya organisasi terhadap Organizational Citizenship Behavior (OCB), makin tinggi pemahaman karyawan tentang budaya organisasi maka semakin mudah perilaku Organizational Citizenship Behavior (OCB) terbentuk.

Berdasarkan uraian hasil penelitian di atas, maka dapat dihipotesiskan : 
$\mathbf{H}_{3}$ : Budaya organisasi berpengaruh positif terhadap Organizational Citizenhip Behavior.

Perilaku organizational citizenship behavior yang dimiliki oleh karyawan berkembang seiring dengan proses sosialisasi nilai-nilai yang ada pada organisasi, ketika nilai-nilai yang dimiliki oleh perusahaan memiliki service value maka organizational citizenship behavior akan muncul pada karyawan (Ahmadi, 2010). Budaya organisasi yang kuat akan mendorong munculnya sense of belonging karyawan pada organisasi, sehingga berdampak pada kinerja karyawan (Robbins,2000).

Khan dan Rashid (2015) dalam penelitiannya menyebutkan bahwa di antara seluruh variabel yang digunakan, komitmen organisasional memiliki pengaruh yang paling kuat terhadap variabel lainnya. Oleh karena itu, dapat dikatakan bahwa komitmen organisasi merupakan variabel mediasi yang baik untuk mengetahui hubungan antara budaya organisasi terhadap Organizational Citizenship Behavior (OCB). Kim (2014) menyebutkan bahwa komitmen afektif secara penuh memediasi antara variabel budaya organisasi dan organizational citizenship behavior pada penelitian yang dilakukan di sektor publik Korea Selatan. Berdasarkan uraian hasil penelitian di atas, maka dapat dihipotesiskan :

$\mathbf{H}_{4}$ : Komitmen Afektif memediasi pengaruh Budaya Organisasi terhadap organizational citizenship behavior.

\section{METODE PENELITIAN}

Metode penelitian ini menggunakan 1 (satu) variabel bebas, 1 (satu) variabel mediasi dan 1 (satu) variabel terikat. Variabel yang digunakan dalam penelitian ini adalah variabel terikat (dependent) yaitu OCB, variabel bebas 
(independent) yaitu Budaya Organisasi, dan variabel mediasi yaitu Komitmen Afektif. Jumlah sampel yang diambil adalah sebanyak 83 (delapan puluh tiga) responden. Sampel yang digunakan dalam penelitian ini diambil dengan menggunakan teknik Proposional Random Sampling, yang ditentukan berdasarkan kriteria Slovin. Metode ini dilakukan dalam rangka mempertahankan derajat representative sampel yang diambil dari populasinya.

Penelitian ini menggunakan pendekatan variance based atau component based dengan Partial Least Square (PLS). Bilamana model struktural yang akan dianalisis memenuhi model rekursif dan variabel laten memiliki indikator yang bersifat formatif, refleksif, atau campuran, maka pendekatan yang paling tepat digunakan adalah $P L S$. Model struktural hubungan antarvariabel laten pada $P L S$ disebut dengan inner model, sedangkan model pengukuran (bersifat refleksif atau formatif) disebut outer model. Metode PLS digunakan dengan pertimbangan karena ukuran sampel tidak terlalu besar.

\section{HASIL DAN PEMBAHASAN}

Penelitian ini menggunakan model persamaan struktural dengan pendekatan Partial Least Square (PLS) sebagai metode analis. Penggunaan PLS sebagai metode analisis mmbutuhkan beberapa tahap pemodelan persamaan struktural. Tahap-tahap pemodelan telah diuraikan pada Bab IV dan model persamaan struktural penelitian ini dapat digambarkan, seperti Gambar 1. 


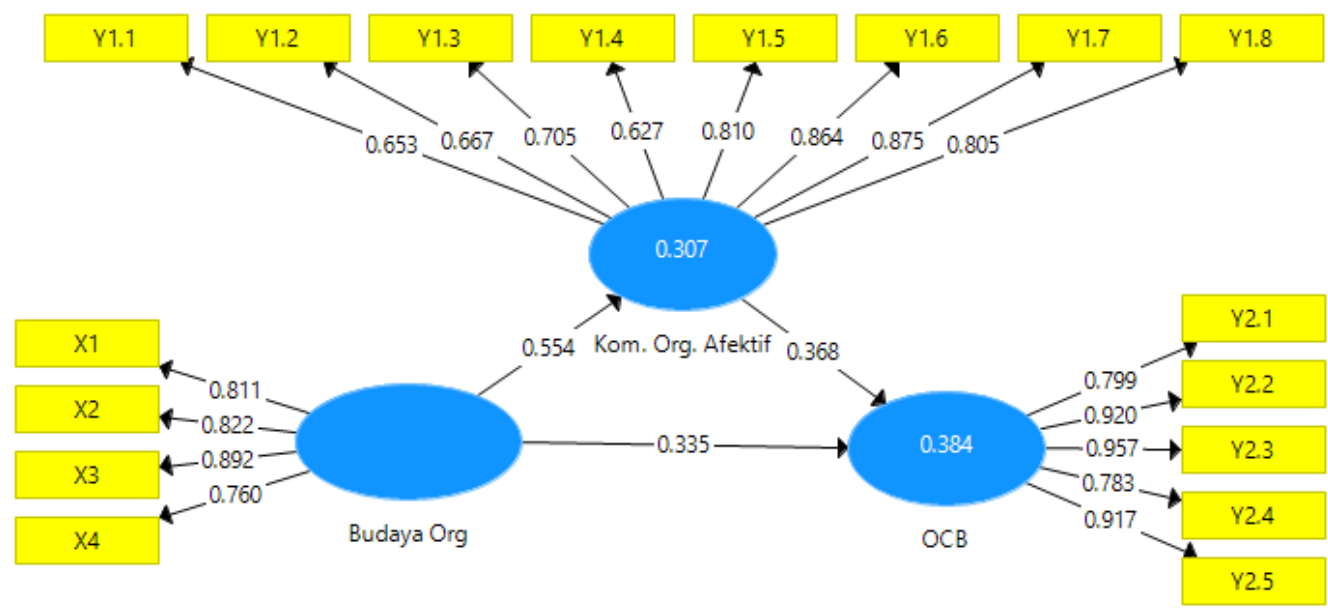

Gambar 1. Model Persamaan Struktural Penelitian

Sumber: Data diolah, 2016

Model struktural tersebut disebut model refleksif dimana covariance pengukuran indikator dipengaruhi oleh konstruk laten atau mencerminkan variasi dari konstruk unidimensional yang digambarkan dengan bentuk elips dengan beberapa anak panah dari konstruk ke indikator. Model ini menghipotesiskan bahwa perubahan pada konstruk laten akan mempengaruhi perubahan pada indikator.

Tabel 2

Outer Loading Variabel Penelitian

\begin{tabular}{|c|c|c|}
\hline Indikator & Proses & Keterangan \\
\hline Keterlibatan (Involvement) $\left(\mathrm{X}_{1}\right)<-$ Budaya Organisasi & 0,811 & Valid \\
\hline Konsistensi (Consistency) $\left(\mathrm{X}_{2}\right)<-$ Budaya Organisasi & 0,822 & Valid \\
\hline $\begin{array}{l}\text { Kemampuan beardaptasi (Adaptibility) }\left(\mathrm{X}_{3}\right)<- \text { Budaya } \\
\text { Organisasi }\end{array}$ & 0,892 & Valid \\
\hline Misi (Mission) $\left(\mathrm{X}_{4}\right)<-$ Budaya Organisasi & 0,760 & Valid \\
\hline Senang menghabiskan sisa karir $\left(\mathrm{M}_{1}\right)<-$ Komitmen Afektif & 0,653 & Valid \\
\hline Bangga membicarakan instansi $\left(\mathrm{M}_{2}\right)<-$ Komitmen Afektif & 0,667 & Valid \\
\hline Merasakan masalah instansi $\left(\mathrm{M}_{3}\right)<-$ Komitmen Afektif & 0,705 & Valid \\
\hline
\end{tabular}




\begin{tabular}{lcc}
\hline Tidak pernah berpikir untuk pindah $\left(\mathrm{M}_{4}\right)<-$ Komitmen Afektif & 0,627 & Valid \\
Merasa menjadi bagian keluarga besar instansi $\left(\mathrm{M}_{5}\right)<-$ & 0,810 & Valid \\
$\begin{array}{l}\text { Komitmen Afektif } \\
\text { Instansi memiliki arti yang sangat penting }\left(\mathrm{M}_{6}\right)<- \text { Komitmen }\end{array}$ & 0,864 & Valid \\
$\begin{array}{l}\text { Afektif } \\
\text { Mempunyai rasa memiliki yang sangat kuat }\left(\mathrm{M}_{7}\right)<- \text { Komitmen }\end{array}$ & 0,875 & Valid \\
Afektif & 0,805 & Valid \\
Merasa terikat secara emosional $\left(\mathrm{M}_{8}\right)<-$ Komitmen Afektif & 0,799 & Valid \\
Altruism $\left(\mathrm{Y}_{1}\right)<-$ OCB & 0,920 & Valid \\
Civic Virtue $\left(\mathrm{Y}_{2}\right)<-$ OCB & 0,957 & Valid \\
Concientiousness $\left(\mathrm{Y}_{3}\right)<-$ OCB & 0,783 & Valid \\
Courtesy $\left(\mathrm{Y}_{4}\right)<-\mathrm{OCB}$ & 0,917 & Valid \\
Sportmanship $\left(\mathrm{Y}_{5}\right)<-$ OCB & &
\end{tabular}

Sumber: Data diolah, 2016

Hasil pengolahan sebagaimana ditunjukkan pada Tabel 2 yang memperlihatkan bahwa nilai outer model telah memenuhi kriteria convergent validity dimana semua indikator memiliki loading factor di atas 0,50 . Hal ini dapat disimpulkan bahwa konstruk mempunyai convergent validity yang baik.

Tabel 3.

Discriminant Validity Budaya Organisasi (X), Komitmen Afektif (Y1) dan OCB (Y2)

\begin{tabular}{cccccc}
\hline Variabel Laten & AVE & VAVE & X & Y1 & Y2 \\
\hline X & 0.677 & 0.823 & 1.000 & 0.000 & 0.000 \\
M & 0.572 & 0.756 & 0.554 & 1.000 & 0.000 \\
Y & 0.771 & 0.878 & 0.539 & 0.554 & 1.000 \\
\hline
\end{tabular}

Sumber: Data diolah, 2016

Data pada Tabel 3 menjelaskan bahwa nilai cross loading menunjukkan adanya discriminant validity yang baik. Hal tersebut dapat dilihat dari nilai korelasi indikator terhadap konstruknya (loading factor) lebih tinggi dibandingkan nilai korelasi indikator tersebut dengan konstruk lainnya. 
Tabel 4.

Uji Reliabilitas Variabel Budaya Organisasi (X), Komitmen Afektif (Y1) dan OCB (Y2)

\begin{tabular}{cccc}
\hline Variabel & Koefisien Cronbach Alpha & Composite Reliability & Keterangan \\
\hline X & 0.840 & 0.893 & Reliabel \\
M & 0.892 & 0.913 & Reliabel \\
Y & 0.924 & 0.944 & Reliabel \\
\hline
\end{tabular}

Sumber: Data diolah, 2016

Berdasarkan Tabel 4, dimana nilai Cronbach Alpha dan nilai Composite Reliability lebih besar dari 0,70, maka dapat dikatakan jawaban-jawaban responden memiliki kosistensi yang cukup tinggi, sehingga seluruh indikator dapat dikatakan reliabel.

Tabel 5.

Nilai $R$-square ( $\left.\mathbf{R}^{2}\right)$ Variabel Laten Endogen

\begin{tabular}{cc}
\hline Variabel & $\mathrm{R}^{2}$ \\
\hline Komitmen Afektif $(\mathrm{M})$ & 0.307 \\
OCB $(\mathrm{Y})$ & 0.384 \\
\hline
\end{tabular}

Sumber: Data diolah, 2016

Berdasarkan Tabel 5 dapat dihitung nilai predictive-relevance $\left(\mathrm{Q}^{2}\right)$, yaitu : 1- $\left(1-0,307^{2}\right)\left(1-0,384^{2}\right)=0,227$. Hasil perhitungan ini menunjukkan bahwa nilai $\mathrm{Q}^{2}$ lebih besar dari $0(0,227>0)$, sehingga dapat diinterpretasikan bahwa model baik karena memiliki nilai prediktif yang relevan, yaitu $22,7 \%$ variasi pada variabel OCB ampu dijelaskan oleh variabel -variabel yang digunakan yaitu variabel budaya organisasi, variabel komitmen afektif, sedangkan sisanya 77,3\% dijelaskan oleh variabel lain yang belum masuk ke dalam model. Interpretasi yang dapat diberikan dari hasil model struktural bahwa komitmen afektif memberikan 
pengaruh paling besar terhadap OCB, yaitu 0,368 , selanjutnya budaya organisasi $(0,335)$.

Tabel 6

Path Coefficient Antara Variabel Budaya Organisasi (X), Komitmen Afektif (Y1) dan OCB (Y2)

\begin{tabular}{llccl}
\hline \multicolumn{1}{c}{ Hubungan Variabel } & Koefisien & T-stat & $\begin{array}{c}\text { P } \\
\text { Values }\end{array}$ & Keterangan \\
\hline Pengaruh Langsung & & & & \\
Budaya Organisasi - > Komitmen Afektif & 0,554 & 6,903 & 0,000 & signifikan \\
Budaya Organisasi -> OCB & 0,335 & 3,162 & 0,002 & signifikan \\
Komitmen Afektif -> OCB & 0,368 & 3,424 & 0,001 & Signifikan \\
Pengaruh Tidak Langsung & & & & \\
Budaya Organisasi -> OCB & 0,204 & 2,952 & 0,003 & signifikan \\
Pengaruh Total & & & & \\
Budaya Organisasi - > Komitmen Afektif & 0,554 & 6,903 & 0,000 & signifikan \\
Budaya Organisasi -> OCB & 0,539 & 5,575 & 0,000 & signifikan \\
Komitmen Afektif -> OCB & 0,368 & 3,424 & 0,001 & Signifikan \\
\hline Sumber: Data diolah, 2016 & & & &
\end{tabular}

Tabel 6 memperlihatkan bahwa budaya organisasi memiliki pengaruh langsung terhadap OCB sebesar 0,335, lebih besar dibandingkan dengan pengaruh tidak langsung terhadap OCB yaitu sebesar 0,204. Komitmen Afektif memiliki pengaruh langsung terhadap OCB sebesar 0,368. Hasil ini menunjukkan bahwa pada kasus tersebut budaya organisasional dan komitmen afektif akan tetap mempengaruhi OCB. Budaya Organisasi memiliki pengaruh total terhadap OCB sebesar 0,539 .

Pengujian hipotesis dilakukan dengan menggunakan uji-t (t-test) pada tiaptiap jalur pengaruh antara variabel bebas dan variabel terikat. Hasil perhitungan jalur (path) secara keseluruhan dapat dilihat pada path coefficients dan total effects. Pengujian hipotesis dalam penelitian ini menggunakan model persamaan struktural PLS Smart 3. Pengujian terhadap hipotesis dalam metode PLS dilakukan dengan menggunakan simulasi terhadap setiap hubungan yang 
dihipotesiskan, dalam hal ini dilakukan metode bootstrap terhadap sampel. Metode bootstrap juga berfungsi untuk meminimalkan masalah ketidaknormalan data penelitian yang digunakan. Pada penelitian ini telah ditentukan sebelumnya nilai T-tabel dengan signifikansi 5\% atau 0,05. Semua koefisien jalur pada Tabel 5.9 memiliki nilai $\mathrm{p}$ value di bawah 0,05 sehingga dinyatakan memiliki pengaruh yang signifikan. Pengujian masing-masing hipotesis dibahas pada sub berikut ini.

Hasil pengujian hipotesis pertama menunjukkan bahwa koefisien jalur pengaruh Budaya Organisasi terhadap Komitmen Afektif adalah sebesar 0,544 dengan nilai t-statistik sebesar 6,903 dan $\mathrm{p}$ value sebesar 0,000 . Nilai $\mathrm{p}$ value tersebut lebih kecil dari 0,05 yang menunjukkan bahwa ada pengaruh yang signifikan antara variabel budaya organisasi terhadap komitmen afektif. Koefisen jalurnya yang bernilai positif menunjukkan bahwa budaya organisasi berpengaruh positif terhadap komitmen afektif. Semakin kuat budaya organisasi maka komitmen afektif juga semakin tinggi. Hal ini berarti Hipotesis 1 diterima.

Hasil pengujian hipotesis kedua menunjukkan bahwa koefisien jalur pengaruh Komitmen Afektif terhadap Organizational Citizenship Behavior (OCB) adalah sebesar 0,368 dengan nilai t-statistik sebesar 3,424 dan $\mathrm{p}$ value sebesar 0,001 . Nilai $\mathrm{p}$ value tersebut lebih kecil dari 0,05 yang menunjukkan bahwa ada pengaruh yang signifikan antara variabel komitmen afektif terhadap Organizational Citizenship Behavior (OCB). Koefisen jalurnya yang bernilai positif menunjukkan bahwa Komitmen Afektif berpengaruh positif terhadap Organizational Citizenship Behavior (OCB). Semakin tinggi komitmen afektif 
maka Organizational Citizenship Behavior (OCB) juga semakin tinggi. Hal ini berarti Hipotesis 2 diterima.

Hasil pengujian hipotesis ketiga menunjukkan bahwa koefisien jalur pengaruh Budaya Organisasi terhadap Organizational Citizenship Behavior (OCB) adalah sebesar 0,335 dengan nilai t-statistik sebesar 3,162 dan $\mathrm{p}$ value sebesar 0,002. Nilai $\mathrm{p}$ value tersebut lebih kecil dari 0,05 yang menunjukkan bahwa ada pengaruh yang signifikan antara variabel Budaya Organisasi terhadap Organizational Citizenship Behavior (OCB). Koefisen jalurnya yang bernilai positif menunjukkan bahwa Budaya Organisasi berpengaruh positif terhadap Organizational Citizenship Behavior (OCB). Semakin kuat budaya organisasi maka OCB juga semakin tinggi. Hal ini berarti Hipotesis 3 diterima.

Tabel 7.

Perhitungan VAF Hubungan Tidak Langsung Variabel Budaya Organisasi Terhadap OCB melalui Komitmen Afektif

\begin{tabular}{lll}
\hline & \multicolumn{1}{c}{ Hubungan Variabel } & Koefisien \\
\hline Pengaruh Langsung & Budaya Organisasi -> OCB (tanpa pemediasi) & 0,539 \\
Pengaruh Tidak Langsung & Budaya Organisasi -> Komitmen Afektif & 0,554 \\
& Komitmen -> OCB & 0,368 \\
& Pengaruh Tidak Langsung=0,554x0,368 & 0,204 \\
Pengaruh Total & Budaya Organisasi -> OCB (0,539+0,204) & 0,743 \\
VAF & Pengaruh Tidak Langsung/Pengaruh Total & 0,274 \\
& $(0,204 / 0,743)$ & \\
\hline
\end{tabular}

Sumber: Data diolah, 2016

Tabel 7 memperlihatkan VAF yang diperoleh pada hubungan tidak langsung variabel budaya organisasi terhadap Organizational Citizenship Behavior (OCB) melalui komitmen afektif adalah sebesar 0,274 (27,4\%). Hasil ini menunjukkan bahwa variabel komitmen afektif memiliki pengaruh mediasi secara parsial terhadap hubungan budaya organisasi dan Organizational Citizenship Behavior 
(OCB). Hasil pengujian hipotesis keempat menunjukkan bahwa koefisien jalur pengaruh tidak langsung Budaya Organisasi terhadap Organizational Citizenship Behavior (OCB) melalui Komitmen Afektif adalah sebesar 0,204 dengan nilai tstatistik sebesar 2,952 dan $\mathrm{p}$ value sebesar 0,003. Nilai $\mathrm{p}$ value tersebut lebih kecil dari 0,05 yang menunjukkan bahwa variabel Komitmen Afektif secara parsial memediasi pengaruh variabel Budaya Organisasi terhadap Organizational Citizenship Behavior (OCB). Hal ini berarti Hipotesis 4 diterima.

Hasil pengujian hipotesis membuktikan bahwa budaya organisasi berpengaruh positif terhadap komitmen afektif. Terdapat hubungan searah antara budaya organisasi dengan komitmen afektif, yaitu semakin tinggi nilai-nilai budaya yang dimiliki dan dikembangkan pada Sekretariat Daerah Kabupaten Badung maka akan semakin tinggi tingkat komitmen afektif para pegawai dan sebaliknya, semakin rendah nilai-nilai budaya yang dimiliki dan dikembangkan pada Sekretariat Daerah Kabupaten Badung maka akan semakin rendah tingkat komitmen afektif yang dimiliki oleh para pegawai yang bertugas pada Sekretariat Daerah Kabupaten Badung.

Hasil tersebut mengindikasikan bahwa nilai-nilai yang terkandung dalam budaya organisasi yang meliputi budaya pemberian kesempatan kepada pegawai untuk lebih berperan aktif dalam kegiatan organisasi, konsistensi organisasi dalam menerapkan atiran organisasi, kemampuan organisasi dalam beradaptasi terhadap perkembangan yang terjadi di masyarakat serta adanya kejelasan arah, tujuan, sasaran dan prosedur kerja mampu memunculkan rasa bangga dan kepercayaan pegawai, meningkatkan keterikatan emosional para pegawai pada organisasinya 
serta menimbulkan perasaan bahwa organisasi ini adalah keluarganya. Komitmen afektif yang meningkat ditandai dengan meningkatnya rasa bangga telah menjadi bagian dari organisasi, tingginya ikatan emosional pegawai terhadap organisasinya, rendahnya keinginan pegawai untuk dipindahkan ke instansi lain.

Penelitian ini membuktikan bahwa budaya organisasi berpengaruh terhadap komitmen afektif, dan hasil ini diperkuat oleh studi dari Kim (2014) mengenai pengaruh budaya organisasi terhadap komitmen afektif, diperoleh kesimpulan bahwa ada pengaruh yang positif dan signifikan antara budaya organisasi terhadap komitmen afektif. Hasil penelitian Momeni et al.(2012) mengenai pengaruh budaya organisasi terhadap komitmen organisasional dari Denison (1990), diperoleh kesimpulan bahwa terdapat hubungan yang signifikan antara semua komponen budaya organisasi yang meliputi adaptability, involvement, adjustment, mission dan komitmen organisasional. Menurut Antonio dan Miguel (2013), adanya penyesuaian yang lebih baik antara persepsi budaya organisasi dan nilainilai yang telah dianut organisasi memiliki hubungan yang positif terhadap komitmen organisasional.

Penelitian juga konsisten dengan hasil penelitian Rahmani et al.(2015) dan Sabri et al. (2011). Rahmani et al. (2015) melakukan studi mengenai hubungan antara budaya organisasi dan komitemen organisasional pada karyawan beberapa rumah sakit yang berada di wilayah Teheran, dan menyatakan bahwa terdapat hubungan yang signifikan antara budaya organisasi dan komitmen organisasional. Penelitian yang dilakukan Sabri et al. (2011) terhadap tenaga pengajar di berbagai institusi pendidikan di universitas di Pakistan menyatakan bahwa budaya 
organisasi memiliki hubungan positif dan signifikan terhadap komitmen organisasional.

Hasil pengujian hipotesis membuktikan bahwa komitmen afektif berpengaruh positif terhadap Organizational Citizenship Behavior (OCB). Terdapat hubungan yang searah antara komitmen afektif dengan OCB yaitu semakin kuat tingkat komitmen afektif para pegawai pada Sekretariat Daerah Kabupaten Badung maka semakin tinggi Organizational Citizenship Behavior (OCB) para pegawai tersebut dan sebaliknya, semakin rendah komitmen afektif pegawai maka akan semakin rendah OCB pegawai pada Sekretariat Daerah Kabupaten Badung.

Hasil penelitian mengindikasikan bahwa para pegawai yang memiliki komitmen afektif yang kuat, yang ditandai dengan adanya kebanggaan dan ikatan emosional yang tinggi pada organisasi, merasa bahwa organisasi memiliki arti yang sangat penting dan menganggap bahwa organisasi seperti keluarganya sendiri dan masalah yang dihadapi oleh organisasi dianggap sebagai masalahnya sendiri, akan memunculkan kerelaan mereka serta peran ekstra dalam melakukan pekerjaan-pekerjaan di luar deskripsi pekerjaannya. Peningkatan nilai Organizational Citizenship Behavior (OCB) para pegawai tersebut dapat dilakukan dengan cara meningkatkan komitmen afektif para pegawai yang bertugas pada Sekretariat Daerah Kabupaten Badung. Hal yang paling menonjol dari indikator variabel komitmen afektif pada penelitian ini adalah adanya perasaan bahwa menjadi bagian dari keluarga besar dalam Sekretariat Daerah serta Sekretariat Daerah memiliki arti yang sangat penting dalam hidup pegawai. 
Dari perasaan yang muncul pada pegawai terhadap Sekretariat Daerah tersebut memunculkan rasa cinta dan penghargaan terhadap Sekretariat Daerah, sehingga ada kemauan untuk melakukan pekerjaan yang melebihi dari Tugas dan fungsinya, tentu saja hal ini dengan satu tujuan yaitu untuk memberikan pelayanan terbaik kepada masyarakat sehingga tujuan organisasi tercapai.

Penelitian ini sejalan dengan hasil penelitian yang telah dilakukan oleh Kim (2014), yang melakukan penelitiannya terhadap pegawai yang bertugas di sector public di Korea Utara diperoleh hasil bahwa Komitmen Afektif berpengaruh positif dan signifikan terhadap Organizational Citizenship Behavior (OCB). Salehi dan Gholtash (2011), Khan dan Rashid (2012), Davoudi (2012). Manurut Salehi dan Gholtash (2011) yang melakukan studi pada bidang akademis, diperoleh hasil bahwa komitmen organisasional berpengaruh positif terhadap Organizational Citizenship Behavior (OCB), semakin besar komitmen anggota fakultas terhadap akademisinya, makin besar Organizational Citizenship Behavior (OCB) anggota yang diharapkan. Khan dan Rashid (2012) menyatakan bahwa dari beberapa variabel bebas yang digunakan sebagai pembentuk Organizational Citizenship Behavior (OCB), komitmen organisasional merupakan variabel yang paling berpengaruh dan secara signifikan mampu menjelaskan Organizational Citizenship Behavior (OCB) karyawan.

Penelitian Davoudi (2012) terhadap karyawan asuransi di Iran, menunjukkan bahwa affective commitment dan normative commitment memberikan implikasi positif terhadap Organizational Citizenship Behavior (OCB), sedangkan continuance commitment berpengaruh tidak signifikan 
terhadap Organizational Citizenship Behavior (OCB). Sjahruddin dan Sudiro (2013); Rehan dan Islam (2013); Suparjo dkk (2013) juga menyatakan bahwa terdapat hubungan yang positif dan langsung antara komitmen organisasional dan Organizational Citizenship Behavior (OCB).

Hasil pengujian hipotesis membuktikan bahwa budaya organisasi berpengaruh positif terhadap Organizational Citizenship Behavior (OCB). Hubungan antara budaya organisasi dengan Organizational Citizenship Behavior (OCB) merupakan hubungan yang searah, yaitu semakin tinggi nilai-nilai budaya yang dimiliki dan dikembangkan pada Sekretariat Daerah Kabupaten Badung maka akan semakin tinggi Organizational Citizenship Behavior (OCB) para pegawai yang ada pada organisasi tersebut dan sebaliknya, semakin rendah nilainilai budaya yang dimiliki dan dikenbangkan pada Sekretariat Daerah maka akan semakin rendah Organizational Citizenship Behavior (OCB) para pegawai yang ada pada Sekretariat Daerah Kabupaten Badung.

Hasil tersebut mengindikasikan bahwa nilai-nilai yang terkandung dalam budaya organisasi yang meliputi budaya pemberian kesempatan kepada pegawai untuk lebih berperan aktif dalam kegiatan organisasi, konsistensi organisasi dalam menerapkan atiran organisasi, kemampuan organisasi dalam beradaptasi terhadap perkembangan yang terjadi di masyarakat serta adanya kejelasan arah, tujuan, sasaran dan prosedur kerja akan mampu memunculkan kerelaan para pegawai dalam melakukan pekerjaan-pekerjaan di luar deskripsi pekerjaan mereka. Perilaku Organizational Citizenship Behavior (OCB) pegawai yang meningkat ditandai dengan meningkatnya perilaku untuk membantu rekan kerja agar 
terhindar dari perselisihan, pengabdian atau dedikasi yang tinggi pada pekerjaan serta bertanggung jawab untuk terlibat, berpartisipasi dan peduli dalam berbagai kegiatan yang diselenggarakan organisasi.

Secara empiris variabel budaya organisasi terbukti berpengaruh terhadap Organizational Citizenship Behavior (OCB), sehingga hasil penelitian ini mendukung hasil penelitian sebelumnya yang dilakukan oleh Ahmadi (2010), Erkutlu (2011) dan Embrahimpour et al. (2011). Ahmadi (2010) menyatakan bahwa budaya organisasi yang didasarkan pada hasil studi hofstede, yang dikategorikan sebagai factor eksternal pembentuk Organizational Citizenship Behavior (OCB), memiliki pengaruh penting terhadap Organizational Citizenship Behavior (OCB) karyawan. Hasil penelitian ini juga sejalan dengan hasil penelitian Karam dan Kwantes (2011) dalam studinya tentang kontekstualisasi orientasi budaya dan Organizational Citizenship Behavior (OCB), yang menyatakan bahwa dalam konteks budaya organisasi, dimensi ideosentris dan keterlibatan karyawan dalam organisasi memiliki hubungan yang positif terhadap Organizational Citizenship Behavior (OCB). Mohant dan Rath (2012) yang melakukan penelitian pada tiga bidang organisasi yaitu manufaktur, perbankan dan teknologi informasi menyatakan bahwa terdapat hubungan yang signifikan antara budaya organisasi dan Organizational Citizenship Behavior (OCB) pada ketiga jenis organisasi tersebut.

Hasil pengujian hipotesis membuktikan bahwa komitmen afektif secara parsial memediasi pengaruh antara budaya organisasi terhadap Organizational Citizenship Behavior (OCB). Hasil tersebut mengindikasikan bahwa nilai-nilai 
yang terkandung dalam budaya organisasi yang meliputi budaya pemberian kesempatan kepada pegawai untuk lebih berperan aktif dalam kegiatan organisasi, konsistensi organisasi dalam menerapkan aturan organisasi, kemampuan organisasi dalam beradaptasi terhadap perkembangan yang terjadi di masyarakat serta adanya kejelasan arah, tujuan, sasaran dan prosedur kerja akan mampu memunculkan kerelaan para pegawai dalam melakukan pekerjaan-pekerjaan di luar deskripsi pekerjaan mereka dengan dimediasi oleh komitmen afektif sehingga menimbulkan keterikatan secara emosional pegawai terhadap organisasinya, hal ini semakin meningkatkan peran ekstra pegawai untuk perperilaku diluar tupoksinya.

Budaya organisasi yang diterapkan di Sekrtariat Daerah Kabupaten Badung yaitu adanya kemampuan berasdaptasi dari organisasi terhadap perkembangan masyarakat yang dicerminkan dengan arah dan tujuan dari Sekretariat Daerah Kabupaten Badung yang sangat jelas. Kebijakan dan program yang disususn oleh Sekretariat Daerah Kabupaten Badung semuanya adalah untuk kepentingan masyarakat Kabupaten Badung. Tentu saja semua hal tersebut melahirkan perasaan bangga para pegawai yang bertugas di Sekretariat Daerah Kabupaten Badung. Perasaan bangga yang muncul itu karena para pegawai merasa organisasinya sudah berperan besar untuk kemajuan masyarakat Kabupaten Badung. Sehingga hal tersebut menciptakan perasaan bahwa Sekretariat Daerah Kabupaten Badung memiliki arti yang sangat penting bagi para pegawai. Perasaan bangga dan cinta terhadap organisasi menyebabkan pegawai dapat berperan lebih 
untuk organisasinya diluar dari tugas dan fungsi mereka yang telah ditetapkan oleh organisasi sebelumnya.

Sesuai dengan hasil penelitian yang dilakukan oleh Kim (2014) yang memasukkan komitmen afektif sebagai pemediasi untuk pengaruh tidak langsung antara budaya organisasi dan Organizational Citizenship Behavior (OCB), dimana hasilnya adalah komitmen afektif memediasi secara parsial antara budaya organisasi dengan Organizational Citizenship Behavior (OCB).

\section{SIMPULAN}

Berdasarkan hasil penelitian dan pembahasan pada bab sebelumnya maka dapat disimpulkan beberapa hal sebagai berikut : 1). Hasil analisis dan pembahasan secara keseluruhan pada penelitian ini menunjukkan bahwa budaya organisasi berpengaruh langsung terhadap komitmen afektif dan Organizational Citizenship Behavior (OCB), begitu pula komitmen afektif berpengaruh langsung terhadap Organizational Citizenship Behavior (OCB). Variabel komitmen afektif memediasi secara parsial pengaruh antara budaya organisasi terhadap Organizational Citizenship Behavior (OCB); 2). Budaya organisasi berpengaruh positif terhadap komitmen afektif pegawai pada Sekretariat Daerah Kabupaten Badung. Semakin tinggi nilai-nilai budaya yang dimiliki dan dikembangkan pada Sekretariat Daerah maka akan meningkatkan komitmen afektif para pegawai yang bertugas di Sekretariat Daerah Kabupaten Badung; 3). Komitmen afektif berpengaruh positif terhadap Organizational Citizenship Behavior (OCB). Semakin tinggi komitmen afektif yang dimiliki pegawai maka semakin tinggi kemauan untuk berperan ekstra dalam melaksanakan tugasnya bagi para pegawai 
yang bertugas di Sekretariat Daerah Kabupaten Badung; 4). Budaya organisasi berpengaruh positif terhadap Organizational Citizenship Behavior (OCB) pegawai. Semakin tinggi nilai-nilai budaya yang dimiliki dan dikembangkan pada Sekretariat Daerah Kabupaten Badung maka akan meningkatkan Organizational Citizenship Behavior (OCB) pegawai yang bertugas pada Sekretariat Daerah Kabupaten Badung; 5). Komitmen afektif memediasi pengaruh budaya organisasi terhadap Organizational Citizenship Behavior (OCB). Semakin tinggi nilai-nilai budaya yang dimiliki dan dikembangkan pada Sekretariat Daerah Kabupaten Badung dan dengan dimediasi oleh komitmen afektif sehingga ditunjukkan dengan sikap pegawai yang memikili keterikatan emosional terhadap organisasinya maka akan meningkatkan Organizational Citizenship Behavior (OCB) atau peran ekstra pegawai yang bertugas pada Sekretariat Daerah Kabupaten Badung.

Saran yang dapat diberikan berdasarkan hasil penelitian adalah sebagai berikut : 1). Para pejabat eselon 3 atau Kepala Bagian serta pejabat eselon IV atau Kasubag. mampu menerapkan budaya organisasi yang memberikan kesempatan keterlibatan para pegawai atau staf dalam proses perencanaan sampai pada batas tertentu dan keterlibatan staf dalam setiap kegiatan yang dilaksanakan oleh organisasi. Program yang dimiliki oleh Sekretariat Daerah diharapkan memiliki budaya organisasi yang selalu berorientasi pada kepentingan public atau masyarakat serta memiliki arah, tujuan, sasaran serta prosedur kerja yang jelas yang dapat dimengerti oleh seluruh pegawai. 


\section{REFERENSI}

Ahmadi, F. 2010. Survey relationship between OCB and internal \& external factors impact on OCB, European Journal of Social Sciences, Volume 16, Number 3

Allen, N. J., and Meyer, J. P. 1991. A Three Component Conceptualization of Organizational Commitmen. Human Resource Management. Review 1, 61-89

Aldag, R., and Reschke, W. 1997. Employee value added: Measuring Discretionary Effort and its Value to the Organization. Center for Organization Effectiveness.

Balvand, Z. A., Parisa Naeimian Monfared, Vahid Farhadi Changhazardi, Fariba Karamian, Fattahi Samareh. 2015. The Relationship Between Emotional Intellegence and Organizational Commitment, Organizational Citizenship Behavior in Secondary Schools in the city of Kermanshah. Journal of Applied Environmental and Biological Science.Vol.5(2).pp.76-82.

Cameron, K., and Quinn R.E. 2006. Diagnosing and Changing Organizational Culture; Based On The Competing Values Framework. Beijing China Rennin University Press.

Darsana, M. 2013. The Influence of Personality And Organizational Culture On Employee Performance Through Organizational Citizenship Behavior. The International Journal of Management 2, 35-42.

Denison, D.R. 1990. Corporate culture and organizational effectiveness. John Wiley \& Sons Corporate. England.

Denison, D.R., and Aneil K Mishra. 1995. Toward a theory of organizational culture and effectiveness. JSTOR. INFORM: Organizational science Vol 6 No.2.

Dipaola, M., and Tschannen Moran, M. 2001. Organizational citizenship behavior in schools and its relationship to school climate. Journal of School Leadership 11, 424-447.

Durkin, M., and Hadyn Bennet. 1999. Employee commitment in retail banking: identifying and exploring hidden dangers, The International Journal of Bank Marketing, Vol 17, No 3, pp. 124-137. 
Ebrahimpour, H., Adel Zahed, Ali Khaleghkhah A, Mohammad Bager Sepehri. 2011. A Survey Relation Between Organizational Culture and Organizational Citizenship Behavior. Procedia-Social and Behavioral Science 30, 1920-1925.

Erkutlu, H. 2011. The moderating role of organizational culture in the relationship between organizational justice and organizational citizenship behaviors. Leadership \& Organization Development Journal 32, 1920-1925.

Ghozali, I. 2008. Model Persamaan Struktural Konsep dan Aplikasi dengan Program Amos 16.0. Badan Penerbit UNDIP, Semarang

Harwiki, W. 2013. The Influence of Servant Leadership on Organization Culture, Organizational Commitment, Organizational Citizenship Behavior and Employees' Performance (Study of Outstanding Cooperatives in East Java Province, Indonesia). Journal of Economics and Behavioral Studies 5, 876885.

Huang, C.C., You C.S., Tsai M.T. 2012. A Multidimensional analysis of ethical climate, job satisfaction, organizational commitment, and organizational citizenship behaviors. Nursing Ethics 19, 513-529.

Hofstede, G., Bram Neuijen, Ohayv, D.D., Sanders, G. 1990. Measuring organizational cultures: A qualitative and quantitative study across twenty cases. Administrative Science Quarterly 35, 286-316.

Jagharg, F.Z., G. Hashem, Seyed, E.N., Alireza,S. and F. Zahra. 2012. A Survey on Organizational Culture Based on Stephan Robbin;s Theory (Case Study), 2nd International Conference on Management and Artificial Intelligence, IPEDR Vol.35, Singapore, IACSIT Press.

Jaros, S. 2007. Meyer and Allen Model of Organizational Commitment : Measurement and Issues. The Icfai Journal of Organizational Behavior, Vol. VI, No.4.

John, M.C., and Taylor J.W. 1999. Leadership Style, School Climate, and the Institutional Commitment of Teachers. International Forum, Vol 2, No 1, pp. 25-57.

Khan, S.K., and Rashid, M.Z.A. 2012. The Mediating Effect of Organizational Commitment in the Organizational Culture, Leadership and Organizational Justice Relationship with Organizational Citizenship Behavior: A Study of Academicians in Private Higher Learning Institutions in Malaysia. International Journal Business and Social Science 3, 83-91. 
Kim, H. 2012. Transformational leadership and organizational citizenship behavior in the public sector in South Korea: the mediating role of affective commitment. Local Government Studies, 38(6), 867-892

Kim, H. 2014. Transformational Leadership, Organizational Clan Culture, Organizational Affective Commitment, and Organizational Citizenship Behavior: A Case of South Korea's Public Sector. Journal of Public Organize Rev, 14:397-417

Khan, S.K. and M. Z. Abdul Rashid. 2015. The Mediating Effect Of Organization Commitment In The Organizational Culture, Leadership and Organization Justice Relationship With OCB : A Study Of Academics In Private Higher Learning Institutions In Malaysia. International Journal of Recent Advances In Organizational Behavior And Decision Science (IJRAOB) An Online International Research Journal (ISSN ; 2311 - 3197) 2015 Vol.1, Issue 2.

Khaola, P.P. and Thataone Sebotsa. 2015. Person-Organization Fit, Organizational Commitment and Organizational Citizenship Behavior. Danish Journal of Management and Business Science.pp.67-74.

Kriemadis, T., M. Koniordos, S. Leivadi, C.Mavromatis, N. Kartakoullis, G. Karlis, J. Oncescu. 2008. Organizational Culture In Middle And Upper Level Hotel Units In Greece. International Journal of Sport Management Recreation \& Tourism 1, 31-44.

Kumar, K., A. Bakhshi, and E. Rani. 2009. Linking the Big Five Personality Domains to Organizational Citizenship Behavior. International Journal of Psychological Studies, Vol 1 No 2, pp. 73-81.

Kurniawan, A. 2015. Pengaruh Komitmen Organisasi Terhadap Organizational Citizenship Behavior. Jurnal Manajemen, Vol.15, No.1.

Lum, L., J. Kervin, K. Clark, F.Reid, and W. Sirola. 1998. Explaining nursing turnover intent: job satisfaction, pay satisfaction, or organisational commitment? Journal of Organisational Behaviour, 19(3) 305-320

Lavelle, J.J.Brockner, J.Konovsky, M.A.Price, K. H. Henley, A. B., Taneja A., and Vinekar, V. 2009. Commitment, procedural fairness, and organizational citizenship behavior: a multifoci analysis.Journal of Organizational Behavior, 30(3), 337-357.

MacKenzie, S. B., Podsakoff, P. M., and Rich,G.A. 2001. Transformational and transactional leadership and salesperson performance. Journal of the Academy Marketing Science, 29, 115-134. 
Momemi, M., M. Amir Babak, and V.Saadat. 2012. The Relationship between Organizational Culture and Organizational Commitment in Staff Departement of General Prosecutors of Tehran. International Journal of Business and Social Science 3, 217-221.

Mowday, R.T., R. M. Steers, and L.W. Porter. 1979. The measurement of organizational commitment. Journal of Vacational Behavior 14, 224-247.

Nawangsari, C. I. 2014 Pengaruh Kepemimpinan Transformasional, Pengawasan dan Transparansi Terhadap Kinerja (Studi pada Satuan Kerja Perangkat Daerah Pemerintah Daerah Kab/Kota di Bakorwil IV Provinsi Jawa Timur).Disertasi.Universitas Brawijaya.

Nongo, E.S., and Ikyanyon D.N., 2012. The influence of corporate cu;ture on employee commitment to the organization. International Journal of Business and Management 7, 21-28.

Oemar, Y. 2013. Pengaruh Budaya Organisasi, Kemampuan Kerja dan Komitmen Organisasi Terhadap OCB Pegawai pada Bappeda Kota Pekanbaru. Jurnal Aplikasi Manajemen.Vol.11 No.1

Organ, D.W., 1990. The motivational basis of organizational citizenship behavior. Journal of Research in Organizational Behavior 12, 43-72., Personnel Psychology, Vol 48, No 4, pp. 775-800.

Organ, D.W., and Ryan, K. 1995. A meta-analytic review of attitudinal and dispositional predictors of organizational citizenship behavior, Personnel Psychology, Vol 48, No 4, pp. 775-800.

Organ,D.W., 2006 Organizational Citizenship Behavior. Its Nature, Antecendents, and Consequences. California: Sage Publications, Inc.

Podsakoff, P.M., MacKenzie, S.B., Paine, J.B., and Bachrach, D.G. 2000. Organizational Citizenship Behaviors: A Critical Review of the Theoretical and Empirical Literature and Suggestions for Future Research, Journal of Management, Vol 26, No 3, pp. 513-563.

Rahmatun, T. A., dan Anang Kristyanto. 2014. Pengaruh Gaya kepemimpinan Transformasional dan Komitmen Organisasi terhadap Organizational Citizenship Behavior. Jurnal Ilmu Manajemen.Vol.2 No.1.

Rini, D. P., Rusdarti, dan Suparjo. 2013. Pengaruh Komitmen Organisasi, Kepuasan Kerja dan Budaya Organisasi terhadap Organizational Citizenship Behavior (OCB) Studi pada PT. Plasa Simpanglima Semarang. Jurnal Ilmiah Dinamika dan Bisnis, Vol.1, No.1. 
Robbins, S. P. and Timothy A. Judge. 2013. Organizational Behavior, 15th Edition. London: Pearson International Edition.

Sabri, P.S.U., M. Ilyas, and Z. Amjad. 2011. Organizational Culture and Its Impact on the Job satisfaction of the University Teachers of Lahore. International Journal of Business and Social Science 2, 121-128.

Salehi, M., A. Gholtash. 2011. The relationship between job satisfaction, job burnout and organizational commitment with the organizational citizenship behavior among members of faculty in the Islamic Azad University-first district branches, in order to provide the appropriate model. Procedia-social and behavioral science 15, 306-310.

Shahzad, F., R.A. Luqman, A.R. Khan, and L. Shabbir. 2012. Impact of organizational culture on organizational performance: an overview. Interdisciplinary Journal of Comtemporary Research in Business 3, 975985.

Shweta, J., and J. Srirang. 2010. Determinants of Organizational Citizenship Behavior: A Review of Literature, Journal of Management and Public Policy. Vol 1 No 2, pp. 27-36.

Smith, C.A., D. W. Organ, and J. P. Near. 1983. Organizational citizenship behavior:its nature and antecedents. Journal of Applied Psychology,68,653-663.

Srimulyani, V. A. 2009. Tipilogi dan Anteseden Komitmen Organisasi. Jurnal Ilmiah Widya Wana. 33 (1), 1-20.

Sugiyono. 2014. Metode Penelitian Kuantitatif, Kualitatif dan R\&D. Bandung: Alfabeta.

Umar, H. 2007. Metode Penelitian untuk Skripsi dan Tesis Bisnis. Jakarta: PT. Raja Grafindo Persada.

Tusi, A.S., H. Wang and K. R. Xin. 2006. Organizational culture in China: an analysis of culture dimensions and culture types. Management and Organization Review, 2, 253-268

Wagner, S. L., and M. C. Rush. 2000. Altruistic organizational citizenship behavior: contex, disposisition, and age. Journal of Social Psychology,14(3), 379-391. 